Article

\title{
Poly(lactic acid)/Cellulose Films Produced from Composite Spheres Prepared by Emulsion-Solvent Evaporation Method
}

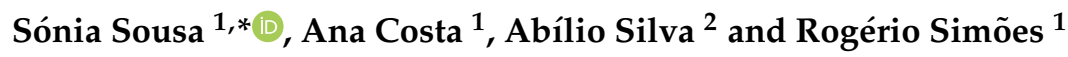 \\ 1 FibEnTech-Fiber Materials and Environmental Technologies Research Unit, Universidade da Beira Interior, \\ Rua Marquês d'Ávila e Bolama, 6201-001 Covilhã, Portugal; anacosta@ubi.pt (A.C.); rmss@ubi.pt (R.S.) \\ 2 C-MAST-Centre for Mechanical and Aerospace Science and Technology, Universidade da Beira Interior, \\ Rua Marquês d'Ávila e Bolama, 6201-001 Covilhã, Portugal; abilio@ubi.pt \\ * Correspondence: scls@ubi.pt; Tel.: +351-275-241-346
}

Received: 28 November 2018; Accepted: 3 January 2019; Published: 4 January 2019

\begin{abstract}
The compound of poly(lactic acid) (PLA) and cellulose was made by the emulsion-solvent evaporation technique in order to obtain spheres which are then compression molded to produce a biocomposite film. The effect of the dispersant (poly(vinyl alcohol)—PVA)/PLA ratio on the spheres yield was studied. Moreover, to evaluate the effect of cellulose particle size and surface chemistry on the process yield, unbleached eucalypt kraft pulp and microcrystalline cellulose (MCC), both unmodified and physically or chemically modified were used. PLA/cellulose spheres were characterized regarding its physical properties. It was found that the spheres yield is essentially determined by the PVA/PLA ratio and the percentage of cellulose incorporation is greatly affected by the surface chemistry of cellulose. Regarding the films, DSC runs showed a significant effect of the cellulose type incorporated into PLA matrix on the cold crystallization temperature and on the degree of crystallinity of the biocomposite films. The measurement of tensile properties of the biocomposite films revealed that the strength, elongation at break and toughness (tensile energy absorption at break) of the films incorporating unmodified and chemically modified MCC were substantially improved.
\end{abstract}

Keywords: poly(lactic acid); pulp fibers; biocomposite; emulsion-solvent evaporation method; films; mechanical properties

\section{Introduction}

In the packaging industry, plastic materials are customizable, easy to process and cheap. The great majority of plastics materials are made up from non-renewable petroleum-based fossil fuels. Due to limited nature of fossil fuels and the growing environmental concern on their use, there is a need for finding more environmentally friendly materials. Currently, the development of biodegradable polymer composites combining biodegradable matrices and natural fibers as reinforcement is of great importance [1]. Starch, poly(caprolactone) (PCL), poly(lactic acid), poly(butylene succinate) (PBS) and poly(hydroxyalkanoates) (PHAs) are most commonly used as matrix phase biopolymers [1-6]. Among the polymer matrices, PLA is one of the most used and at present PLA-based materials find applications in the biomedical, textile and packaging areas [5,7]. PLA is a high molecular weight polyester usually produced by ring-opening polymerization of lactide. The monomer, lactic acid, can be derived from corn, potato, cane, beet sugar or cheese residues by fermentation $[1,3,7]$. The commercial PLA, however, is a brittle material and various reinforcing materials such as natural fibers can be used to improve its toughness [8,9]. In addition, natural fibers as reinforcement materials 
present other advantages as their low density, high specific strength and modulus, nonabrasive character and low cost [3]. Various forms of cellulose have been explored as reinforcements into PLA composites. These include fibers from jute, kenaf, henequen, flax, cotton, bamboo [10-16], wood pulp $[3,4,17]$, microcrystalline cellulose (MCC) $[9,18,19]$ and, micro and nanocellulose in different forms and from different origins [8,20-28]. Due to its hydrophilic nature, cellulose is not easily uniformly dispersed into hydrophobic PLA matrix which leads to poor interfacial adhesion, thus reducing the mechanical properties of the composites $[16,18,22,23]$. To overcome this limitation, many physical or chemical treatments have been applied for cellulose modification. The effect of plasma treatment on interfacial interaction of lyocell fibers in a poly(lactic acid) matrix was investigated [29]. According to Cho et al. [10], natural fibers treated with tap water by static soaking and dynamic ultrasonication, followed by drying leads to PLA composites with improved interfacial shear strength, flexural and dynamic mechanical properties. Treatment of cellulosic fibers with alkali or enzymes were also tested [12,13]. Incorporation of casein protein or bioadimide in cellulose/PLA composites was found to improve the dispersion and fiber/matrix adhesion [15,30]. In addition, Magniez et al. [16] demonstrated that the adsorption of amphiphilic poly(ethylene glycol)-b-poly(L-lactide) block copolymers increases the interfacial affinity in a jute and polylactide biocomposite. Methods such as acetylation, silylation or grafting with other hydrophobic monomers have been used for cellulose surface modification $[6,11,20,31]$. The preparation of microcrystalline cellulose-graft-poly(lactic acid) via melt copolycondensation was carried out by Hua et al. [18]. These authors observed that the microcrystalline cellulose grafting increases the compatibility with PLA matrix thus improving the dispersion of the cellulose. Graupner [12] and Graupner et al. [32] found that the use of lignin in PLA/cellulose fiber composites improved the adhesion between fiber and matrix. Recently, nanofibrillated cellulose with high lignin content was used to enhance the PLA/cellulose compatibility in the composites [33,34].

In addition to cellulose chemical properties and its dispersion in the PLA matrix, the biocomposite properties are also affected by the processing conditions. Melt-compounding is traditionally used for many types of biocomposites as it is fast and easier to scale-up to industrial scale [35]. However, as PLA is sensitive to temperature, shearing and hydrolysis, some precautions are required during the processing step to avoid its degradation [7]. Solvent casting is a simple and widely used technique to prepare cellulose nanocomposites using different matrices, but it is mostly applied at laboratory scale $[7,25,30,35]$. This technique can lead to differences in the properties of the composites compared to another processing methods $[7,36]$. In another approach, a papermaking based process was used, which enables the production of sheets made from aqueous suspension containing a mixture of cellulose fibers or microfibrillated cellulose (MFC) and PLA fibers [8,37]. This process gives good dispersions even at high MFC contents (up to $90 \mathrm{wt} \%$ ) and the composites obtained by compression molding of the stacked sheets presented an increase of tensile properties with the MFC content [8]. The use of PLA microparticles is an alternative to PLA fibers resulting in nanocomposites with good cellulose nanofibers dispersions [20,22]. The production of PLA microparticles was carried out by solvent evaporation technique which is widely used in pharmaceutical industry for drug microencapsulation [22,38,39]. In a typical procedure, a volatile organic phase containing the dissolved polymers is emulsified in an aqueous phase at continuous constant stirring rate. Then, the volatile solvent is gradually evaporated to form the spherical polymer particles [39]. This technique was also used by Lee and Ji [40] to encapsulate hydrophilic entities such as cellulose nanowhiskers and microfibrils within polymeric nano/microspheres. However, to the best of our knowledge, until now the solvent evaporation technique was never used to produce PLA spheres incorporating pulp fibers, which have a much higher size. In another study, Lee et al. [26] developed a method based on thermally induced phase separation to produce composite microspheres of bacterial cellulose with PLA that can be processed in conventional extrusion.

The aim of this work is to produce biocomposite spheres of PLA and both pulp fibers and MCC, using emulsion-solvent evaporation method. In order to evaluate the effect of size and surface 
properties of the pulp fibers, unbleached pulp fibers and the corresponding grinded fibers, either unmodified or surface modified by lignin deposition were used and the effectiveness of cellulose incorporation into PLA spheres was analyzed. MCC and MCC surface modified were also studied. Spheres of the PLA/cellulose biocomposite were characterized for its physical and chemical properties. The produced spheres are processed by compression molding to obtain composite films, which are characterized regarding its thermal, structural and mechanical properties.

\section{Materials and Methods}

\subsection{Materials}

PLA used in this study was Ingeo 2500HP from NatureWorks LLC (Minnetonka, MN, USA) having a density of $1.24 \mathrm{~g} / \mathrm{cm}^{3}$ and relative viscosity of 4.0 (tested at $1.0 \mathrm{~g} / \mathrm{dL}$ in chloroform). Microcrystalline cellulose (MCC) was Avicell ${ }^{\circledR}$ purchased from Merck (Darmstadt, Germany). Hexadecyltrimethylammonium bromide (CTAB) and poly(vinyl alcohol) (PVA, 98-99\% hydrolysis, $\left.M_{\mathrm{w}}=85,000-124,000\right)$ were purchase from Sigma-Aldrich (St. Louis, MO, USA). Dichloromethane (DCM) (Scharlau, Sentmenat, Spain), hydrochloric acid (Merck, Darmstadt, Germany), sulfuric acid (Sigma-Aldrich, USA), potassium permanganate (Merck, Darmstadt, Germany), potassium iodide (VWR, Leuven, Belgium) and sodium thiosulfate pentahydrate (Merck, Darmstadt, Germany) were analytical grade and used as received. The carbohydrate standards D-glucose and $\mathrm{D}(+)$-xylose were acquired from Pronalab (Sintra, Portugal) and Merck (Darmstadt, Germany), respectively. Cellulosic fibers from Eucalyptus globulus unbleached kraft pulp and kraft black liquor were supplied by Celtejo-Empresa de Celulose do Tejo, S.A (Vila Velha de Ródão, Portugal). Kraft black liquor was used as a source of lignin for fiber surface modification. Their organic and inorganic content were $12.7 \%$ and $14.4 \%$, respectively, determined using the standard methods TAPPI 650 om-09 and TAPPI T211 om-02.

\subsection{Cellulose Modification}

The average size of the pulp fibers was modified using the mixer mill CryoMill (Retsch, Haan, Germany). For that, $2.5 \mathrm{~g}$ of unbleached pulp fibers (UP) were grinded at room temperature using one grinding cycle of $2.5 \mathrm{~min}$ at $30 \mathrm{~s}^{-1}$ frequency. This sample will be designated by GUP. The fiber morphology of UP and GUP samples were characterized using the fiber analyzer Morfi (Techpap, Grenoble, France). The arithmetic average fiber length $(\mathrm{mm})$, width $(\mu \mathrm{m})$ and fines content (\% in length) of UP were $0.641,18.7$ and 28.7, whereas the corresponding values for GUP were 0.447, 20.9 and 62.9. Particles with less than $0.2 \mathrm{~mm}$ in length are considered as fines [41]. The mean particle size of MCC was $13 \mu \mathrm{m}$, determined by laser diffraction particle size analyzer (Beckman Coulter, Inc., Brea, CA, USA).

In order to modify the surface chemistry of the cellulose, kraft lignin was precipitated over the MCC and the grinded pulp fibers as follows: $2.5 \mathrm{~g}$ of cellulose in aqueous suspension ( $50 \mathrm{~mL}$ deionized water) was mixed with $50 \mathrm{~mL}$ of black liquor. Then the $\mathrm{pH}$ of the cellulose-lignin was lowered by addition of $5 \mathrm{M} \mathrm{HCl}$ solution, until $\mathrm{pH}$ around 3. The suspension was centrifuged at $3000 \times g$ for $10 \mathrm{~min}$, the supernatant removed and the cellulose modified with lignin was washed three times with deionized water. In order to obtain cellulose samples with different lignin content, an additional assay was carried out using $2.5 \mathrm{~g}$ of GUP suspended in $90 \mathrm{~mL}$ deionized water and $10 \mathrm{~mL}$ of black liquor. These samples were designated as MCC-L61, GUP-L61 and GUP-L25, respectively, where L61 and L25 means the lignin content in the modified cellulosic materials. The lignin content was determined according to TAPPI T236 om-99 standard and was found to be $4.1 \%, 25.4 \%, 60.9 \%$ and $61.4 \%$ for GUP, GUP-L25, GUP-L61 and MCC-L61 samples, respectively. 


\subsection{Preparation and Characterization of PLA/Cellulose Biocomposite Spheres}

In a typical laboratorial procedure, a suitable amount of PVA was dissolved in $110 \mathrm{~mL}$ deionized water containing $0.1 \mathrm{~g}$ CTAB and stirred at $300 \mathrm{rpm}$ using a mechanical stirrer (Heidolph RZR 2021, Schwabach, Germany). Separately, $0.5 \mathrm{~g}$ cellulose fibers was suspended in $50 \mathrm{~mL}$ of deionized water using an IKA ${ }^{\circledR}$ T25 UltraTurra ${ }^{\circledR}$ homogenizer at $10,000 \mathrm{rpm}$ for $1 \mathrm{~min}$, and after this suspension was added to the PVA solution. After homogenization of the PVA and the cellulose fibers, the solution of $2 \mathrm{~g}$ PLA in $40 \mathrm{~mL}$ dichloromethane (previously prepared) was poured into the aqueous suspension producing an oil-in-water emulsion (Figure 1). PVA is commonly used in emulsification solvent evaporation formulations as dispersant to prevent the coalescence of the oil droplets, having been observed that the used amount affects the preparation of microspheres [38,39,42]. Since the cellulose pulp has carboxylic groups, a cationic surfactant (CTAB) was used together with PVA to stabilize the emulsion and to promote cellulose incorporation in the PLA. The amount of CTAB was kept constant and PVA concentration was changed in order to evaluate its effect on the process yield. The system was mechanically stirred at constant rate $(300 \mathrm{rpm})$ for $24 \mathrm{~h}$ at room temperature $\left(20^{\circ} \mathrm{C}\right)$ to evaporate the organic solvent. The spheres were recovered from the liquid phase by sedimentation, thoroughly washed with deionized water in order to remove the dispersants (PVA and CTAB) and dried at $40^{\circ} \mathrm{C}$ for 2 days. An assay without cellulose addition was also carried out using the same procedure, and the PLA spheres were recovered.

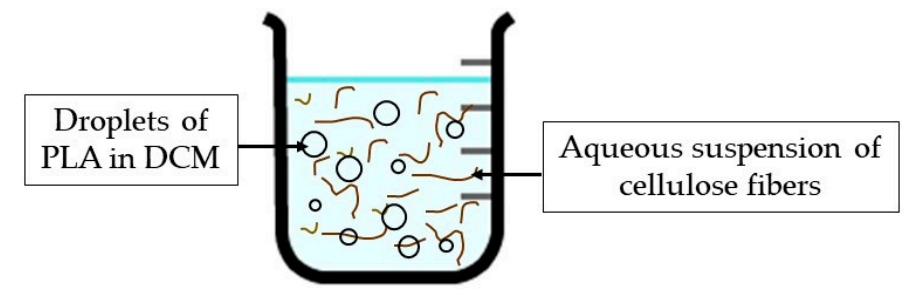

Figure 1. Illustration to show the oil-in-water emulsion in the process to obtain the PLA/cellulose biocomposite spheres.

\subsubsection{Process Yield}

The spheres yield was determined by the ratio of the weight of spheres and the sum of the weight of PLA and cellulose charged in the assay, assuming that the entire amount of dispersants (PVA and CTAB) remains in the liquid phase (supernatant). The amount of cellulose and lignin incorporated in the biocomposite spheres was estimated by mass balance, after measuring their corresponding amounts remaining in the liquid phase after solid separation. Therefore, the percentage of cellulose and lignin incorporation into PLA spheres was calculated by the difference between the initial amount of cellulose and lignin used in each assay and the amount of cellulose and lignin in the liquid phase, regarding the initial charge. The cellulose and lignin in the liquid phase were determined following the standard procedure usual in the wood and pulp filed. For cellulose determination, the NREL procedure (NREL/TP-510-42618) was followed. It should be noted that cellulose term used throughout the work also includes the residual hemicellulose in the pulp fibers. The dissolved lignin in the liquid phase was determined following the TAPPI T236 om-99 standard procedure; a blank test was carried out using the same proportions of PVA and CTAB as those used in the corresponding assay.

\subsubsection{Physical Characterization of PLA/Cellulose Spheres}

The particle size distributions and external specific surface area of the most representative samples of PLA/cellulose spheres was obtained by the laser diffraction method using the Coulter LS200 particle size analyzer (Beckman Coulter Inc., Brea, CA, USA). The density of the spheres was measured by the pycnometer method. Global specific surface area was measured according to the Brunauer-Emmett-Teller (BET) method using ASAP 2000 V2.04 (Micromeritics Instruments Corp., Norcross, GA, USA) apparatus. To further evaluate the morphology of the biocomposite 
spheres, scanning electron micrographs were taken on a Hitachi S-2700 scanning electron microscope (Tokyo, Japan) at $20 \mathrm{kV}$ accelerating voltage. A cross-section of the spheres was obtained by imbedding the spheres into melted paraffin. After complete solidification, the hardened paraffin was cut into pieces using a Microm HM 315 rotary microtome and the sphere slices were washed with xylene. The samples were coated with a gold layer allowing for surface and cross-section visualization.

\subsubsection{Attenuated Total Reflectance-Fourier Transform Infrared Spectroscopy}

The efficiency of chemical surface modification was analyzed by ATR-FTIR spectroscopy. The ATR-FTIR spectra have been recorded on a Thermo Scientific Nicolet iS10 spectrometer (Thermo Fisher Scientific, Waltham, MA, USA) equipped with an ATR unit. The cellulose samples and the PLA/cellulose biocomposite spheres were analyzed in the form of pellets. A total of 64 scans were performed over each sample with a resolution of $4 \mathrm{~cm}^{-1}$. The spectrum was obtained from a range of $600-4000 \mathrm{~cm}^{-1}$.

\subsubsection{Contact Angle Measurements}

In order to determine the changes in the hydrophilic character of the cellulose after surface modification, as well as the hydrophilicity of the PLA/cellulose composite spheres, contact angle measurements were carried out with deionized water using a DataPhysics OCAH 200 system (DataPhysics Instruments GmbH, Filderstadt, Germany) by means of sessile drop method. Uniform and practically porosity-free pellets (obtained by high compression at room temperature) of cellulose and lignin samples and PLA/cellulose spheres were used for this purpose. The initial contact angle was measured after ca. $50 \mathrm{~ms}$ of the water drop fall on the pellet surface. This time may be considered short enough to avoid absorption and thus an equilibrium drop shape could be assumed. All measurements were performed at $22^{\circ} \mathrm{C}$ and each sample was measured with a minimum of four drops.

\subsection{Production and Characterization of Biocomposite Films from PLA/Cellulose Spheres}

The produced biocomposite PLA/cellulose spheres were compression molded into films using a hot press at $180{ }^{\circ} \mathrm{C}$, progressively increasing the compression pressure to $3 \mathrm{MPa}$ for $1 \mathrm{~min}$. This temperature and pressure were kept constant for $1 \mathrm{~min}$. Then, the heating was turned off and the hot press was cooled down to $110^{\circ} \mathrm{C}$ at a rate of $6{ }^{\circ} \mathrm{C} / \mathrm{min}$ using a circulating bath. The pressure was relieved and the film taken out.

\subsubsection{Differential Scanning Calorimetry Analysis}

Thermal properties of the PLA and biocomposite films were analyzed by Differential Scanning Calorimetry (DSC). The analyses were conducted with a Netzsch instrument DSC200 Cell and TASC 414/3 controller (Netzsch-Gerätebau GmbH, Selb, Germany). Samples of about $10 \mathrm{mg}$ were placed in aluminum pans and heated from 30 to $500{ }^{\circ} \mathrm{C}$ at $10^{\circ} \mathrm{C} / \mathrm{min}$ using nitrogen as a purge gas. The degree of crystallinity $\left(X_{c}\right)$ of the film samples was calculated by [43]:

$$
X_{\mathcal{c}}(\%)=\frac{\left(\Delta H_{m}-\Delta H_{c c}\right)}{\Delta H_{m}^{0} \cdot w} \cdot 100
$$

where $\Delta H_{m}$ and $\Delta H_{m}^{0}$ is the melting enthalpy of the sample and of the pure crystalline PLA (93.6 J/g) [25], respectively; $\Delta H_{c c}$ is the cold crystallization enthalpy and $w$ is the weight fraction of PLA in the biocomposite.

\subsubsection{Structural Properties of the Biocomposite Films}

Basis weight was determined by the ratio between the weight and the area of the films according to ISO 536:2012. The films were weighed in an analytical balance $( \pm 0.0001 \mathrm{~g})$. The thickness of the films was measured according to ISO 534:2011 using the micrometer Adamel Lhomargy model MI 20 (Ivry-sur-Seine, France). Apparent density of the biocomposite films corresponds to the ratio between 
the basis weight and the thickness, according to ISO 534:2011. Structural properties were evaluated at $23{ }^{\circ} \mathrm{C}$ and $50 \% \mathrm{RH}$.

\subsubsection{Mechanical Testing of Biocomposite Films}

Tensile tests were performed on a tensile tester Thwing-Albert Instrument Co. (West Berlin, NJ, USA), EJA series based on ISO 1924/2:2008 standard. The biocomposite films were cut into rectangular pieces with $10 \mathrm{~mm}$ wide and $40 \mathrm{~mm}$ length, and then subjected to tensile test at a strain rate of $10 \mathrm{~mm} / \mathrm{min}$, using the initial grip distance of $10 \mathrm{~mm}$. Tensile strength, elongation at break, Young's modulus and toughness (tensile energy absorption at break) were calculated. Bending tests were accomplished on a Lorentzen and Wettre stiffness tester (Stockholm, Sweden) at bending angle of $15^{\circ}$, based on ISO 2493/1:2010 standard and the bending elastic modulus was calculated according to Niskanen [44]. All tests were performed at $23^{\circ} \mathrm{C}$ and $50 \%$ RH.

\section{Results and Discussion}

\subsection{Spheres Yield and Effectiveness of Cellulose Incorporation}

PLA/cellulose biocomposite spheres were successfully obtained (as seen in Figure 2) by solvent evaporation technique with yields ranging from close to 0 to $87.2 \%$ (Table 1 ); this yield represents the percentage of the PLA and cellulose (jointly accounted) recovered as spheres regarding to the initial amounts used.
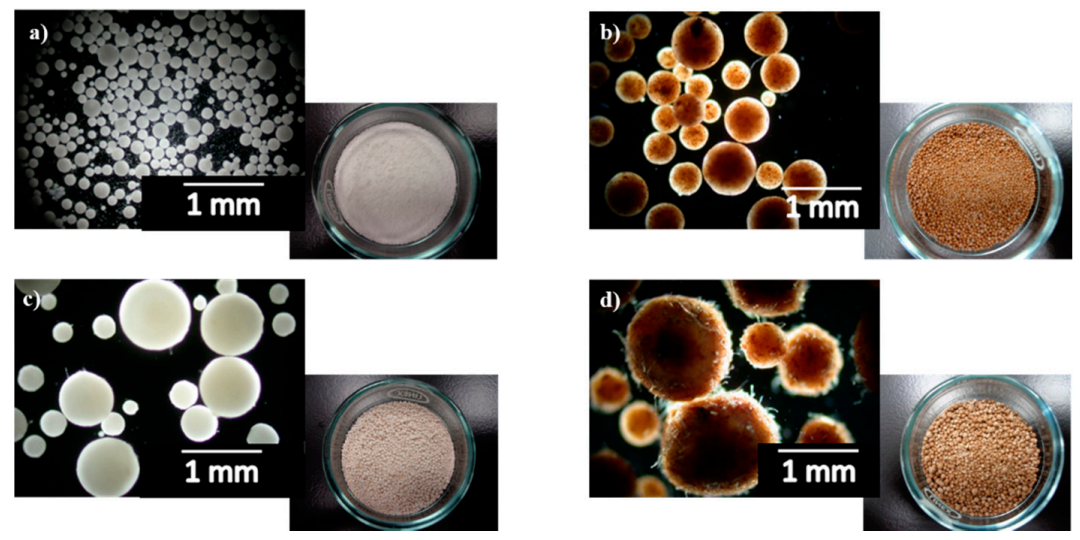

Figure 2. Pictures of some PLA/cellulose biocomposite spheres: (a) PLA/MCC; (b) PLA/MCC-L61; (c) PLA/GUP; (d) PLA/GUP-L61 (see Table 1 for sample identification).

Table 1. Effect of PVA/PLA ratio on PLA/cellulose spheres yield, for different samples (cellulose can be UP: unbleached pulp, GUP-grinded UP, GUP-L25-GUP with 25 wt \% lignin, GUP-L61-GUP with $61 \mathrm{wt} \%$ lignin, MCC-microcrystalline cellulose, MCC-L61-MCC with $61 \mathrm{wt} \%$ lignin).

\begin{tabular}{ccc}
\hline Sample & PVA/PLA Ratio & Spheres Yield (\%) \\
\hline PLA & 0.13 & $36.4 \pm 4.1$ \\
PLA & 0.28 & $85.9 \pm 2.2$ \\
PLA * & 0.35 & $93.2 \pm 0.9$ \\
PLA/UP * & 0.13 & $79.9 \pm 1.2$ \\
PLA/UP & 0.20 & $75.8 \pm 1.2$ \\
PLA/GUP * & 0.13 & $82.8 \pm 3.1$ \\
PLA/GUP & 0.20 & $76.3 \pm 2.1$ \\
PLA/GUP-L25 & 0.28 & $79.6 \pm 0.4$ \\
PLA/GUP-L61 & 0.13 & $7.5 \pm 7.3$ \\
PLA/GUP-L61 & 0.20 & $0 \pm 0$ \\
PLA/GUP-L61 * & 0.28 & $87.2 \pm 1.8$ \\
PLA/MCC & 0.13 & $4.0 \pm 1.5$ \\
PLA/MCC & 0.20 & $4.5 \pm 6.4$ \\
PLA/MCC * & 0.28 & $74.0 \pm 0.3$ \\
PLA/MCC-L61 * & 0.13 & $84.3 \pm 4.3$ \\
\hline * Samples characterized more deeply throughout the work
\end{tabular}

* Samples characterized more deeply throughout the work. 
As observed in Table 1, the PVA/PLA ratio determines the spheres yield, as can be seen for the PLA samples with PVA/PLA ratios of $0.13,0.28$ and 0.35 , the PLA/GUP-L61 samples obtained with $0.13,0.20$ and 0.28 PVA/PLA ratios, and the PLA/MCC samples with $0.13,0.20$ and 0.28 PVA/PLA ratios. When only PLA was used, the increase of PVA/PLA ratio from 0.13 to 0.35 leads to the increase of spheres yield from $36.4 \%$ to $93.2 \%$. For the low PVA/PLA ratio, a significant spheres agglomeration occurs. Increasing the amount of PVA stabilize the emulsion, prevents the droplets coalescence during the dichloromethane evaporation by providing a protective layer around the droplets. Thus, the droplets aggregation into large particles does not occur and the spheres yield increase with higher PVA/PLA ratio. Jiang et al. [42] also observed an increase of PLA nanoparticles yield with the increase of PVA concentration. When the emulsion contains cellulose fibers (original or grinded) besides PLA, the PVA/PLA ratio required to form individualized spheres is lower than those required by PLA only ( 0.13 versus 0.35 ); however the average spheres size is much higher and the external specific surface area much lower (Table 2). Reducing cellulose fiber length from $0.641 \mathrm{~mm}$ (UP) to $0.447 \mathrm{~mm}$ (GUP) with the concomitant increase of the cellulose fine material content (from $28.7 \%$ to $62.9 \%$ ), the spheres yield increased only slightly from $79.9 \%$ to $82.8 \%$ (PLA/UP vs. PLA/GUP), which suggest that the particle dimensions are not a key parameter in spheres yield. In addition, the increase of PVA/PLA ratio from 0.13 to 0.20 (PLA/GUP) does not improve the spheres yield. In the case of MCC, the amount of dispersant required is higher than for the cellulose fibers. For PVA/PLA ratios of 0.13 or 0.20 , the formation of agglomerates of irregular size occurred, providing a very low spheres yield (around $4 \%$ ), whereas with the 0.28 PVA/PLA ratio a spheres yield of $74.0 \%$ was obtained. This high amount of PVA required for spheres formation is in accordance with the very high external specific surface area of these particles (Table 2). In addition, as we will see later on, the MCC incorporation is very low and therefore the droplets are almost only PLA; as a consequence, the PVA/PLA ratios were also of the same magnitude.

Table 2. Physical properties of selected samples of PLA/cellulose spheres (see Table 1 for sample identification).

\begin{tabular}{|c|c|c|c|c|c|}
\hline \multirow{3}{*}{ Sample } & \multirow{3}{*}{$\begin{array}{l}\text { Density } \\
\left(\mathrm{g} / \mathrm{cm}^{3}\right)\end{array}$} & \multicolumn{3}{|c|}{ Laser Diffraction } & \multirow{3}{*}{$\begin{array}{c}\text { BET } \\
\begin{array}{c}\text { Global } \\
\text { Surface Area } \\
\left(\mathrm{cm}^{2} / \mathrm{g}\right)\end{array}\end{array}$} \\
\hline & & \multicolumn{2}{|c|}{ Average Spheres Size $(\mu \mathrm{m})$} & \multirow{2}{*}{$\begin{array}{c}\text { External } \\
\text { Surface Area } \\
\left(\mathrm{cm}^{2} / \mathrm{g}\right)\end{array}$} & \\
\hline & & $\begin{array}{l}\text { Weighted by } \\
\text { Volume }\end{array}$ & $\begin{array}{l}\text { Weighted by } \\
\text { Number }\end{array}$ & & \\
\hline PLA & $0.78 \pm 0.03$ & $126.2 \pm 1.5$ & $46.0 \pm 1.9$ & $525.0 \pm 21.2$ & not measured \\
\hline PLA/UP & $0.91 \pm 0.03$ & $796.5 \pm 1.3$ & $633.4 \pm 1.3$ & $78.3 \pm 0.4$ & 10,600 \\
\hline PLA/GUP & $0.69 \pm 0.01$ & $611.1 \pm 1.4$ & $447.2 \pm 1.3$ & $104.5 \pm 0.7$ & 11,400 \\
\hline PLA/GUP-L61 & $0.77 \pm 0.01$ & $888.0 \pm 1.4$ & $648.4 \pm 1.4$ & $71.1 \pm 0.2$ & 9300 \\
\hline PLA/MCC & $0.78 \pm 0.00$ & $130.9 \pm 1.6$ & $10.9 \pm 1.6$ & $579.7 \pm 11.3$ & 5700 \\
\hline PLA/MCC-L61 & $0.83 \pm 0.02$ & $641.7 \pm 1.4$ & $305.5 \pm 1.9$ & $101.0 \pm 4.5$ & 7400 \\
\hline
\end{tabular}

In addition to spheres yield, it is important to investigate the cellulose material incorporation into the spheres composite. The PLA:cellulose ratio initially charged into the medium was fixed at 80:20. The cellulose incorporation was calculated by mass balance (charged cellulose-cellulose recovered in the liquid phase after solid/spheres recover), regarding the cellulose charged, and the corresponding values are in Figure 3.

Grinding the cellulose fibers led to a small increase in incorporation (from 31.4\% to 36.0\%, Figure 3), which suggests that the particle dimension is not the main parameter determining the cellulose fibers incorporation. According to Maa and Hsu [45] and Al-Azzam et al. [46], the incorporation of solid protein particles $(0.4-79 \mu \mathrm{m}$ particle sizes) in poly(metyl methacrylate) and poly(lactic-co-glycolic acid) polymers was improved with decreasing protein particle size. It was also found that the protein particle with irregular shape resulted in microspheres with lower amount of protein than if protein particles are spherical, for protein particle size higher than $5 \mu \mathrm{m}$. For finer particle, the effect was 
less significant [45]. In the present work, the UP and GUP fibers have irregular shape and their sizes $(641$ and $447 \mu \mathrm{m})$ are much higher than the protein particle sizes used in the abovementioned work $(0.4-79 \mu \mathrm{m})$. Considering their size, the behavior of microcrystalline cellulose (MCC) is at first glance unexpected, because the lowest incorporation was observed despite its lowest average particle size $(13 \mu \mathrm{m})$. This result demonstrates the low affinity of pure cellulose to the PLA (dissolved in dichloromethane). On the contrary, the unbleached pulp fibers (UP and GUP) even with a very small amount of lignin (4.1\%), exhibit higher affinity to PLA. These results observed in the emulsion are in agreement with those reported for the solid phase. In fact, several authors [10,32,33], stated that lignin can be used as coupling agent in cellulose fiber reinforced composites as it improves chemical interactions between the cellulose fiber and PLA matrix through non-polar groups.

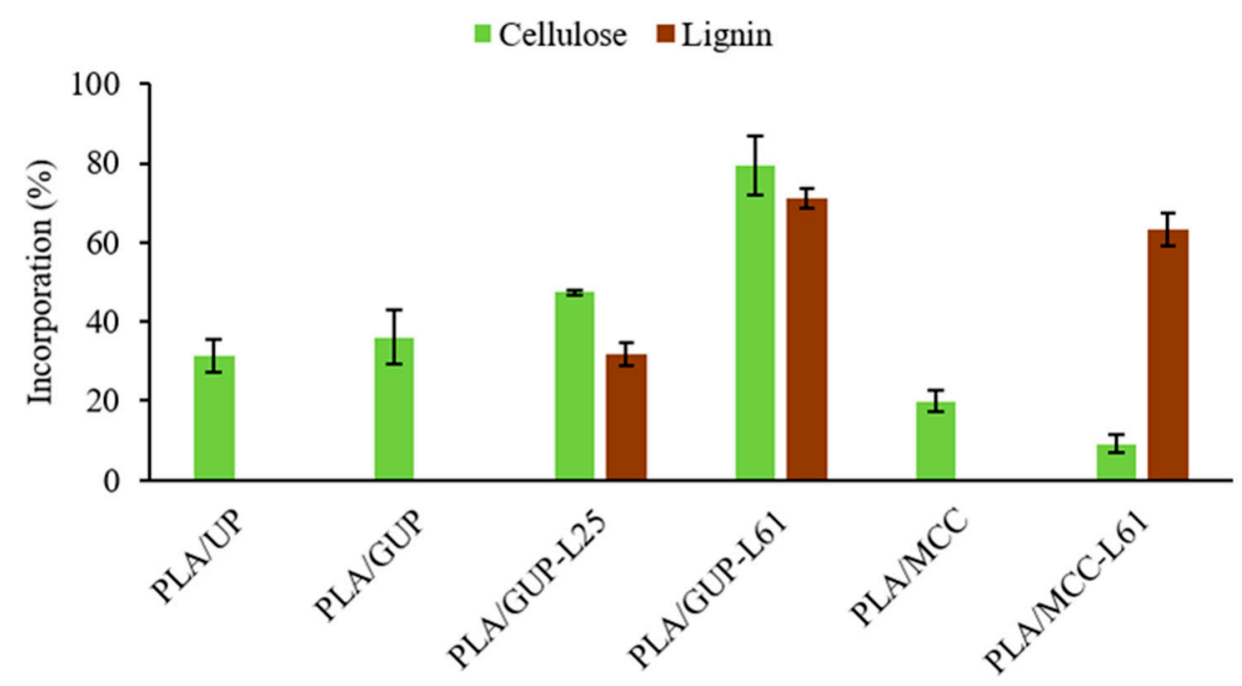

Figure 3. Cellulose and lignin incorporation (based on the corresponding amounts initially charged) into the PLA spheres (see Table 1 for abbreviations).

Therefore, the other approach exploited in this work was the cellulose fibers surface modification, using a natural product, kraft lignin. Kraft lignin is a sub-product of the kraft pulp production process, easily removed from the black liquor (a side stream of the process) by acidification. In wood, lignin has an important hydrophobic character; in the kraft process it is partially depolymerized and chemically modified in order to make it soluble in strong alkaline medium. By acidification it turns again water insoluble and can be adsorbed on the fibers. This lignin, however, is not hydrophobic according to the standard definition (surface having a water contact angle greater than $90^{\circ}$ ), as the water contact angle measured in the lignin pellets was around $57^{\circ}$. Nevertheless, this value is higher than those measured on MCC $\left(41.2^{\circ}\right)$ and unbleached pulp pellets $\left(48.3^{\circ}\right)$.

In order to investigate the effect of this surface modification on both the spheres yield and cellulose incorporation into PLA spheres, MCC and grinded pulp fibers (GUP) with precipitated lignin were prepared. Comparing GUP (without precipitated lignin) and GUP-L61 (with precipitated lignin) samples in Table 1, it was observed that for the pulp fibers with 61\% lignin (GUP-L61), the PVA/PLA ratio should be increased from 0.13 to 0.28 in order to obtain individualized spheres with a yield of $87.2 \%$. For a PVA/PLA ratio of 0.13 or 0.20 , practically only formation of agglomerates occurred. A possible explanation for the higher PVA/PLA ratio required may be the more hydrophobic nature of lignin; PLA alone also requires high PVA/PLA ratio. During the dichloromethane evaporation, the coalescence of the droplets may occur by hydrophobic affinity, leading to a higher amount of PVA required to prevent the aggregation of the GUP with adsorbed lignin. Concerning to the MCC, unmodified and modified with 61\% lignin (MCC vs. MCC-L61), it was found that the presence of lignin decreases the PVA/PLA ratio required for the formation of individualized spheres from 0.28 to 0.13 , with a spheres yield of $84.3 \%$, but the average spheres size (weighted in volume) increased from 
131 to $642 \mu \mathrm{m}$ (Table 2) and the corresponding external specific surface area decreased from 580 to $101 \mathrm{~cm}^{2} / \mathrm{g}$. Considering that the GUP-L61 sample had required a PVA/PLA of 0.28 , it was not expected that the PVA/PLA ratio of 0.13 would be enough for MCC-L61 sample, even because the external specific surface areas of the two samples are of the same magnitude. As it is well known in paper technology that the cohesion energy of fiber flocks increases with fiber length, we can speculate that higher PVA/PLA ratio is required to counterbalance the cohesion energy of the long fibers, regarding the MCC particles (447 $\mu \mathrm{m}$ vs. $13 \mu \mathrm{m})$.

Regarding cellulose fibers incorporation (Figure 3), for the GUP fibers it was observed an increase of cellulose incorporation from $36.0 \%$ to $79.4 \%$ with the increase of lignin content from $4 \%$ to $61 \%$. Moreover, the lignin retention exhibits a similar trend. In other words, the pulp fiber incorporation in the PLA spheres increases from $36 \%$ to over $70 \%$, with the increase of the fiber lignin content. For the MCC, the behavior is the opposite; there is a decrease when the cellulose is modified with lignin (Figure 3). This result may be due to desorption of the previously precipitated lignin on the MCC, by preferential dissolution in dichloromethane. On the other hand, the high lignin incorporation (63.1\%) in the PLA spheres is a clear indication of the high affinity of the lignin to the PLA (see, also Table 3).

Based on the amount of cellulose and lignin charged and the corresponding incorporation, the content of each component in the composite spheres was calculated and the values are presented in Table 3. It was observed that the cellulose content in the spheres ranged from 1.0 to $8.8 \%$, with pulp fibers in clear advantage.

Table 3. Composition of the PLA/cellulose biocomposite spheres (see Table 1 for sample identification).

\begin{tabular}{cccc}
\hline Sample & $\begin{array}{c}\text { PLA } \\
\mathbf{( \% )}\end{array}$ & $\begin{array}{c}\text { Cellulose } \\
(\mathbf{\% )}\end{array}$ & $\begin{array}{c}\text { Lignin } \\
\mathbf{( \% )}\end{array}$ \\
\hline PLA/UP & 92.8 & 7.2 & $\approx 0$ \\
PLA/GUP & 92.2 & 7.8 & $\approx 0$ \\
PLA/GUP-L25 & 89.1 & 8.8 & 2.0 \\
PLA/GUP-L61 & 82.7 & 7.2 & 10.1 \\
PLA/MCC & 95.0 & 5.0 & 0 \\
PLA/MCC-L61 & 88.1 & 1.0 & 10.9 \\
\hline
\end{tabular}

\subsection{Physical Characterization of PLA/Cellulose Spheres}

Some of the most representative samples of PLA/cellulose biocomposite spheres (indicated in Table 1 by asterisks) were characterized concern to physical properties, namely density, particle size distributions and external specific surface area (Table 2). All samples presented multimodal particle size distributions (Figure 4). PLA spheres size range between 20 and $325 \mu \mathrm{m}$ with low average size (126.2 $\mu \mathrm{m}$ and $46.0 \mu \mathrm{m}$, respectively weighted in volume and number) with a high external specific surface area of $525 \mathrm{~cm}^{2} / \mathrm{g}$ (Table 2). The incorporation of unbleached pulp (PLA/UP) provides particles size ranging from 390 to $1400 \mu \mathrm{m}$ with an average size of $796.5 \mu \mathrm{m}$ (volume weighted) and $633.4 \mu \mathrm{m}$ (number weighted), close to the magnitude of the fiber length. The external specific surface area of these spheres, determined by laser diffraction technique, was $78.3 \mathrm{~cm}^{2} / \mathrm{g}$. The grinding of the pulp fibers (PLA/GUP sample) results in spheres with smaller size (average size volume weighted of $611.1 \mu \mathrm{m}$ and number weighted of $447.2 \mu \mathrm{m}$ ) than PLA/UP spheres. The lower average size provides a higher external specific surface area for the PLA/GUP spheres compared with original unbleached pulp (PLA/UP) $\left(104.5 \mathrm{~cm}^{2} / \mathrm{g}\right.$ versus $78.3 \mathrm{~cm}^{2} / \mathrm{g}$ ). Thus, it can be concluded that fibers with lower length $(0.447 \mathrm{~mm})$ yields smaller spheres than the corresponding original fibers (average fiber length of $0.641 \mathrm{~mm}$ ). As reported in Table 2, the incorporation of grinded pulp fibers modified by lignin precipitation produces spheres with the largest average size $(888.0 \mu \mathrm{m}$ and $648.4 \mu \mathrm{m}$, respectively weighted in volume and number) with a size distribution ranging from 370 to $1900 \mu \mathrm{m}$. Notice that these spheres have average size higher than those obtained by incorporation of original pulp fibers. Moreover, they also present the lowest external specific surface area $\left(71.1 \mathrm{~cm}^{2} / \mathrm{g}\right)$. Thus, the spheres size is not only affected by the size of the incorporated fibers but also by their surface chemistry. 
PLA/MCC spheres differ from the others biocomposite spheres by having the smallest size weighted in volume and in number (130.9 $\mu \mathrm{m}$ and $10.9 \mu \mathrm{m}$, respectively). The modification of MCC with lignin leads to spheres with much higher size than MCC (average size increases from 130.9 to $641.7 \mu \mathrm{m}$, weighted in volume, and from 10.9 to $305.5 \mu \mathrm{m}$ weighted in number) and lower external specific surface area $\left(101.0 \mathrm{~cm}^{2} / \mathrm{g}\right)$.
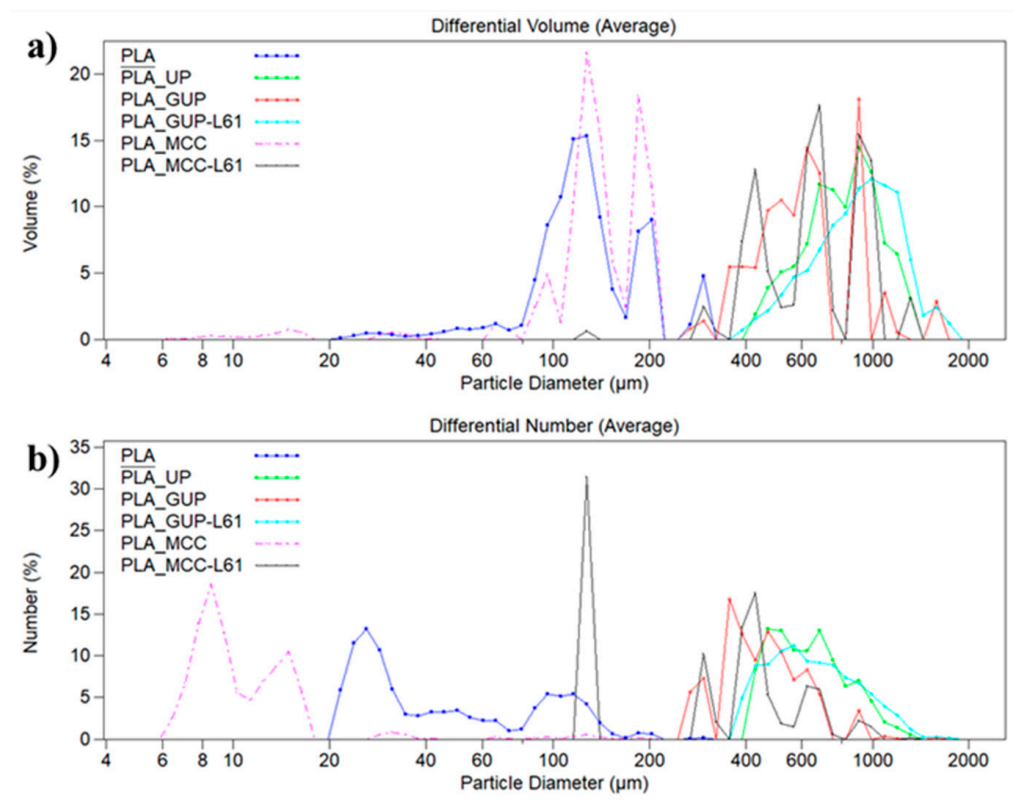

Figure 4. Particle size distributions in volume (a) and in number (b) for some PLA/cellulose biocomposite spheres (see Table 1 for abbreviations).

The global (external and internal) specific surface area provided by BET analysis is one or two orders of magnitude higher than those obtained by laser diffraction. This is an expected result due to the surface roughness and the internal porosity, accounted by BET analysis, and also revealed by the SEM images (Figures 5 and 6). The PLA/UP sample exhibits a high roughness due to the presence of the larger fibers, whereas others such as PLA and PLA/MCC-L61 are much smoother. All the biocomposite spheres are spherical except in the case of PLA/UP sample. The cross-sections of the spheres (Figure 6) show that the inner structure has some pores, presenting the PLA/UP sample a more compact structure. The internal porosity observed in Figure 6 is in good agreement with the spheres density $\left(0.69-0.91 \mathrm{~g} / \mathrm{cm}^{3}\right.$, Table 2$)$, which is significantly lower than the $1.24 \mathrm{~g} / \mathrm{cm}^{3}$ reported for the PLA used in the present study.
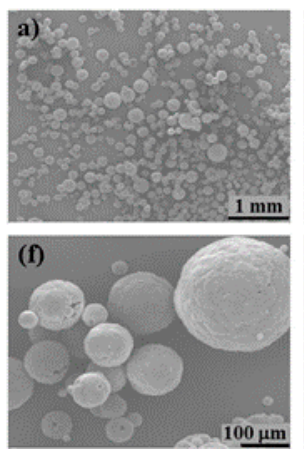
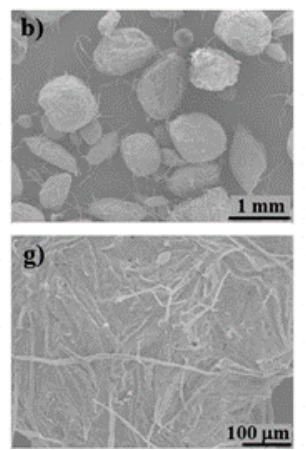
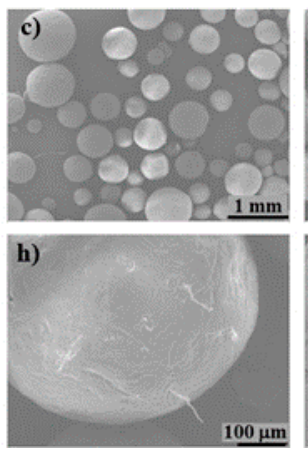
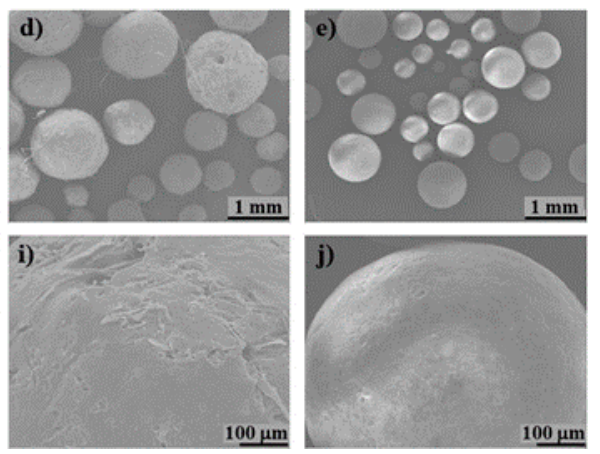

Figure 5. SEM images of the surface morphology of biocomposite spheres: $(\mathbf{a}, \mathbf{f})$ PLA; $(\mathbf{b}, \mathbf{g})$ PLA/UP); (c,h) PLA/GUP; (d,i) PLA/GUP-L61; (e,j) PLA/MCC-L61; (a) 200× and (f) 1000× magnification; (b-e) $25 \times$ and $(\mathbf{g}-\mathbf{j}) 200 \times$ magnification (see Table 1 for sample identification). 

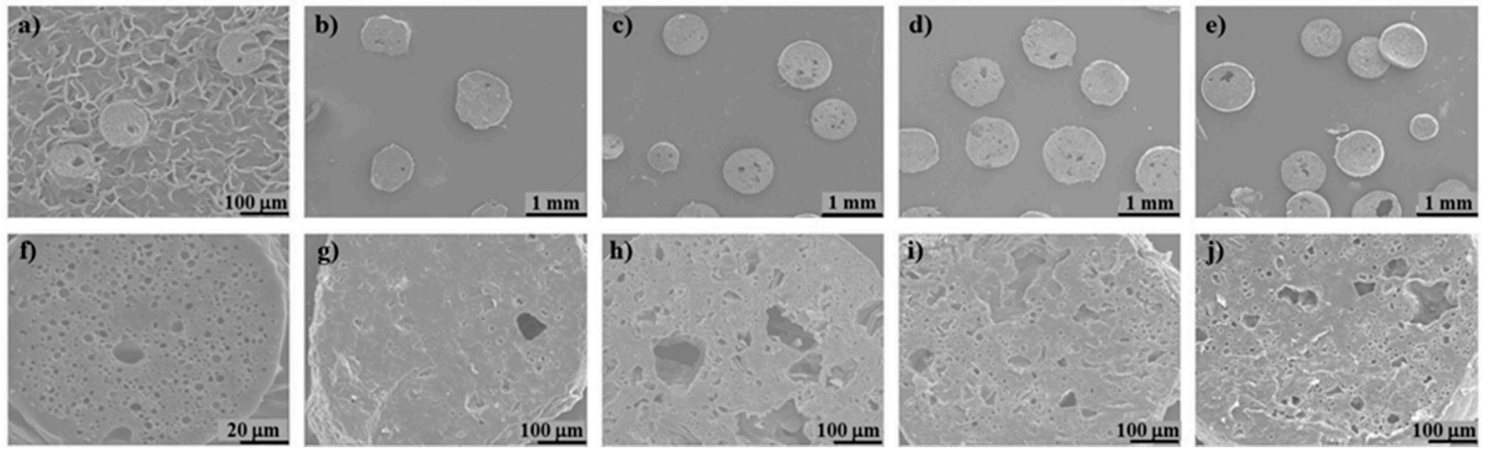

Figure 6. SEM images of the inner structure of biocomposite spheres: (a,f) PLA; (b,g) PLA/UP; (c,h) PLA/GUP; (d,i) PLA/GUP-L61; (e,j) PLA/MCC-L61; (a) 200× and (f) 1000× magnification; (b-e) $25 \times$ and $(\mathbf{g}-\mathbf{j}) 200 \times$ magnification (see Table 1 for sample identification).

\subsection{Chemical Characterization of PLA/Cellulose Spheres}

Surface chemistry induced by the chemical modifications of the cellulose samples as well as of the PLA/cellulose biocomposite spheres were investigated by ATR-FTIR (spectra in Figure 7). When compared with MCC, ATR-FTIR spectrum of unbleached pulp fibers showed an additional band at $1590 \mathrm{~cm}^{-1}$ characteristic of lignin which is associated to aromatic ring vibration [32,47]. Both spectra exhibit the typical bands of cellulose, namely the broad band at $3331-3333 \mathrm{~cm}^{-1}$ attributed to the $\mathrm{OH}$ stretching vibration of intramolecular hydrogen bonds [32,48]. The spectra of GUP and MCC modified with precipitated lignin (GUP-L61 and MCC-L61) showed new peaks (at 1605 and $1608 \mathrm{~cm}^{-1}$, respectively) comparatively to GUP and MCC spectra, assigned to lignin [47,48], confirming the lignin adsorption. PLA spectrum showed distinctive absorption bands assigned to their different functional groups, corresponding the major peak at $1748 \mathrm{~cm}^{-1}$ to the $\mathrm{C}=\mathrm{O}$ stretching vibration [49]. The biocomposite spheres spectra confirm the presence of lignin (peak around 1598-1605 $\mathrm{cm}^{-1}$ ), cellulose (for example, the peak around 3331-3347 $\mathrm{cm}^{-1}$ ) and PLA (for example the peak around $1707-1708 \mathrm{~cm}^{-1}$ ). The PLA/MCC spectrum is very similar to that of PLA due to the very low incorporation of MCC into the spheres (these are constituted by 95\% PLA). Comparing the spectra of the cellulose samples and PLA/cellulose biocomposites, it was observed a decrease in the intensity of the peak assigned to $\mathrm{OH}$ stretching vibration (around 3331-3347 $\mathrm{cm}^{-1}$ ) for the biocomposites, as expected. Compared to the PLA, the wavenumber of $\mathrm{C}=\mathrm{O}$ peak in the biocomposites remains practically unchanged (1748 vs. $1747 \mathrm{~cm}^{-1}$ for PLA/MCC-L61 sample) suggesting a relatively weak interaction between cellulose (UP, GUP-L61 and MCC-L61) and PLA. 

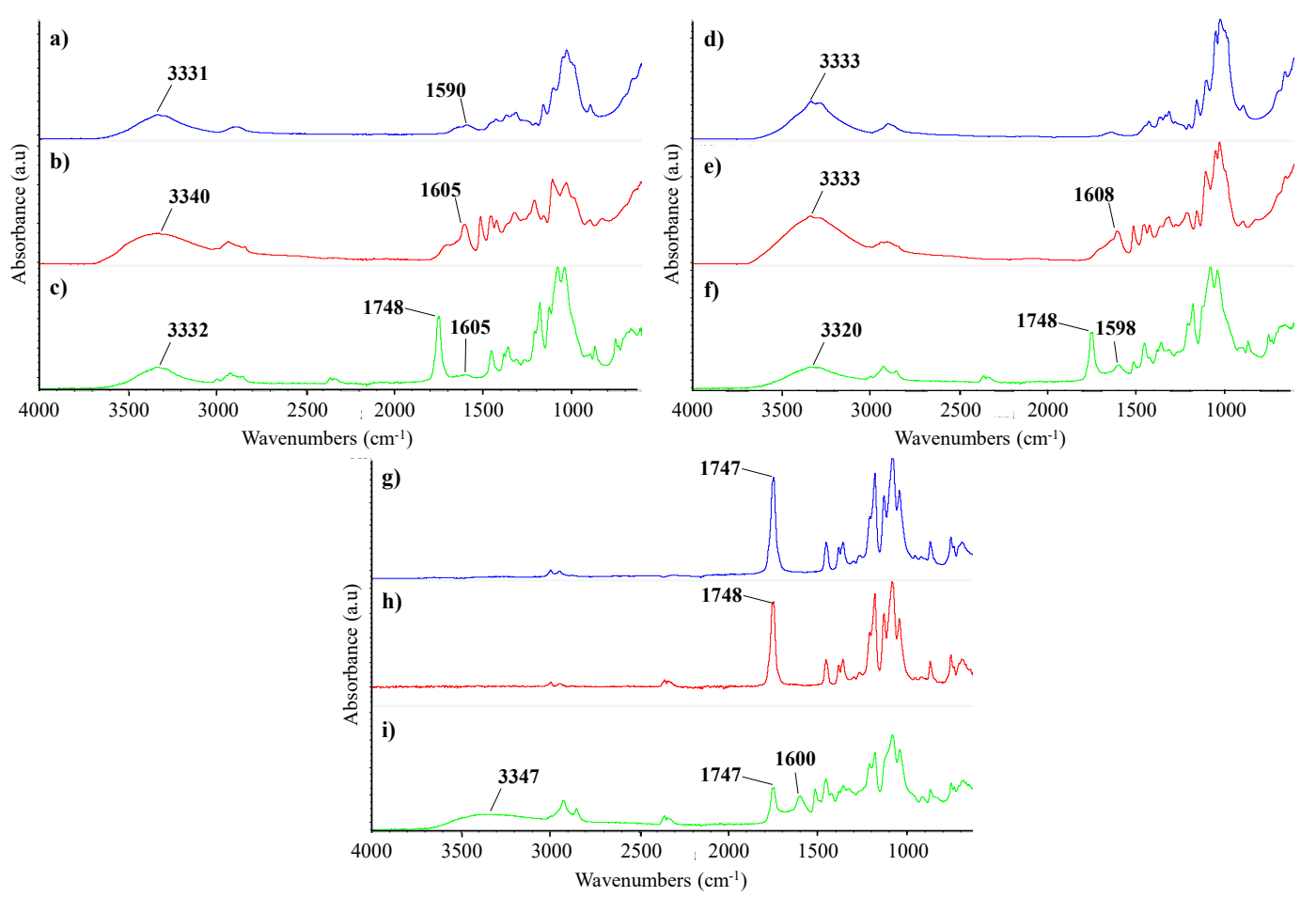

Figure 7. ATR-FTIR spectra of cellulose samples, PLA and biocomposite spheres: (a) UP or GUP; (b) GUP-L61; (c) PLA/UP; (d) MCC; (e) MCC-L61; (f) PLA/GUP-L61; (g) PLA; (h) PLA/MCC; (i) PLA/MCC-L61 (see Table 1 for abbreviations).

Figure 8 shows the water contact angle for the starting materials and the composites spheres as well, measured in pellets produced under high pressure $(0.9 \mathrm{GPa})$ at room temperature in order to preserve the chemistry and minimize the porosity and roughness of the pellet which both affect contact angle measurement. By this way, the contact angle reflects mainly the chemistry of the material. MCC presents the lowest water contact angle $\left(41.2^{\circ}\right)$, which is the most hydrophilic sample. In turn, unbleached pulp presents a higher contact angle $\left(48.3^{\circ}\right)$ due to the presence of residual lignin. As expected, the lignin precipitation on the cellulose fibers and MCC increases very significantly the water contact angle. For the unbleached pulp, the contact angle increases from $48.3^{\circ}$ to $75.4^{\circ}$ (GUP-L25; around $25 \%$ lignin) and then decreases to $59.6^{\circ}$ (GUP-L61; around $61 \%$ lignin). This decrease from $75.4^{\circ}$ to $59.6^{\circ}$ is probably due to the co-precipitation of sugar-lignin complex for the more concentrated black liquor solution. In fact, the lignin precipitated from the more diluted solution exhibited a darker tone than that precipitated from the more concentrated solution, despite the same final $\mathrm{pH}$ value used $(\mathrm{pH}=3)$. Comparing the unbleached fibers and MCC, before and after lignin precipitation, we can observe a very significant increase of the water contact angle, although none samples have reached hydrophobic character (water contact angle higher than $90^{\circ}$ ), they have a contact angle value much closer to that of PLA which is $83.3^{\circ}$, consistent with those found in literature [50,51]. Thus, it would be expected that chemically modified cellulose samples were more compatible with PLA than those unmodified, resulting in higher percentage of cellulose incorporation (Figure 3). This behavior was in fact confirmed for GUP-L25 and GUP-L61, pulp fibers. For the microcrystalline cellulose reversible lignin desorption in aqueous medium was reported by Maximova et al. [52], which render the MCC-L61 sample hydrophilic and with low affinity to PLA; on the contrary, the desorbed lignin was strongly retained in the PLA (see Figure 3 and Table 3). Regarding the contact angles for the PLA/cellulose biocomposite spheres, the values are always inferior to that of PLA, ranging from $59.0^{\circ}$ to $75.0^{\circ}$ for PLA/MCC and PLA/MCC-L61 samples, respectively. Overall, the cellulose samples with higher contact angle leads to the corresponding PLA/cellulose spheres with slightly higher contact angle. 


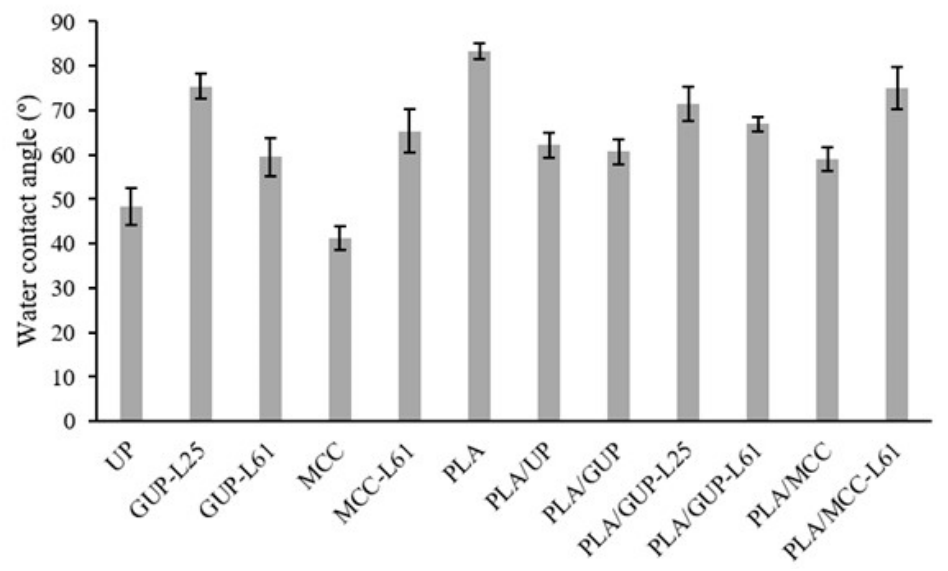

Figure 8. Water contact angle of cellulose samples, PLA and PLA/cellulose biocomposite spheres (see Table 1 for abbreviations).

\subsection{Characterization of the Biocomposite Films}

Composite spheres were compression molded into films and these were characterized concerning their thermal, structural and mechanical properties. Thermal properties were investigated via DSC. The DSC curves are depicted in Figure 9 and were used to determine the glass transition temperature $\left(T_{g}\right)$, cold crystallization temperature $\left(T_{c c}\right)$, cold crystallization enthalpy $\left(\Delta H_{c c}\right)$, melting temperature $\left(T_{m}\right)$, melting enthalpy $\left(\Delta H_{m}\right)$ and degradation temperature $\left(T_{d}\right)$ of the different samples. At the end of the DSC test, the aluminum pans were weighed in order to determine the solid residue at $500{ }^{\circ} \mathrm{C}$. These results are shown in Table 4 along with the degree of crystallinity $\left(X_{c}\right)$. It can be seen that the PLA exhibited a $T_{g}$ at $62.1^{\circ} \mathrm{C}$ and the composite films have a slightly lower $T_{g}$, except the PLA/MCC-L61 film (1\% cellulose) that presented similar $T_{g}$ to the PLA. The decrease of the $T_{g}$ signifies that cellulose incorporation increases the chain mobility of the PLA polymer. It was also observed that the PLA fraction undertaken cold crystallization in the DSC test is composite dependent. For example, the original cellulose fiber (UP) led to the smallest cold crystallization peak (Figure 9), but the film exhibits the highest PLA crystallinity degree (Table 4). This indicates that this composite had favorable conditions to crystallize in the film making process. The contrary occurred for the composite incorporating grinded UP (GUP). Compared with PLA, the cold peaks shifts to lower temperatures for PLA/UP, PLA/GUP and PLA/MCC composites, indicating that cold crystallization occurs earlier induced by UP, GUP and MCC which act as nucleating agents for PLA crystallization, in good agreement with results reported by other authors $[26,43,53,54]$. On the contrary, the presence of lignin in the cellulose materials (PLA/GUP-L61 and PLA/MCC-L61) led to higher $T_{c c}$. This result is in agreement with reported by Gordobil et al. [50] which found that the introduction of lignin in the PLA matrix affects the crystallization behavior causing that the PLA chains have a lower mobility and crystallize with greater difficult and higher temperatures. According to the reported by Graupner [12] and Graupner et al. [32], lignin improves the fiber/matrix adhesion, which may explain the decrease of the mobility of the PLA chains, and consequently hindering the crystallization process leading to composites with lower crystallinity and higher values of $T_{c c}$ as well. Frone et al. [54] observed a similar behavior in PLA nanocomposites reinforced with silane treated nanofibers.

The incorporation of lignin in the composites has also a very favorable impact on the composite thermal stability, as we can see in Figure $9\left(325-385^{\circ} \mathrm{C}\right)$. The extent of degradation is substantially reduced taking into account the value of the endothermic transition. The solid residue at $500{ }^{\circ} \mathrm{C}$ is also higher due to the formation of highly condensed aromatic structures which have the ability to form char [55]. The rise of the residue at $500{ }^{\circ} \mathrm{C}$ with the addition of lignin into PLA composites was reported in other studies [56]. 


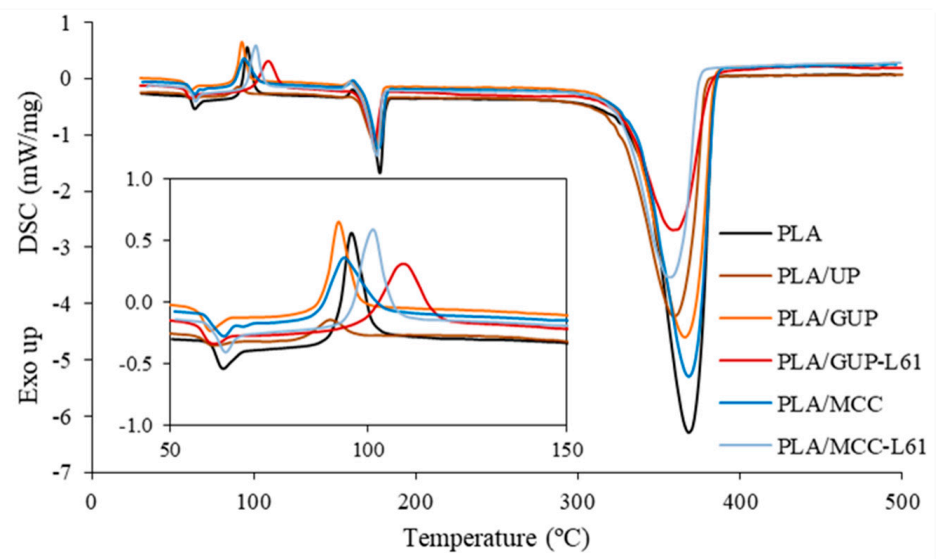

Figure 9. DSC curves of PLA and biocomposite films with the crystallization region in the insert (see Table 1 for abbreviations and Table 3 for composite composition).

Table 4. DSC parameters for PLA and its biocomposite films (see Table 1 for sample identification).

\begin{tabular}{ccccccccc}
\hline Sample & $\boldsymbol{T}_{\boldsymbol{g}}\left({ }^{\circ} \mathbf{C}\right)$ & $\boldsymbol{T}_{c c}\left({ }^{\circ} \mathbf{C}\right)$ & $\boldsymbol{\Delta} \boldsymbol{H}_{c c}(\mathbf{J} / \mathbf{g})$ & $\boldsymbol{T}_{\boldsymbol{m}}\left({ }^{\circ} \mathbf{C}\right)$ & $\boldsymbol{\Delta} \boldsymbol{H}_{\boldsymbol{m}}(\mathrm{J} / \mathbf{g})$ & $\boldsymbol{X}_{\boldsymbol{c}}(\%)$ & $\boldsymbol{T}_{\boldsymbol{d}}\left({ }^{\circ} \mathrm{C}\right)$ & $\begin{array}{c}\text { Solid } \\
\text { Residue (\%) }\end{array}$ \\
\hline PLA & 62.1 & 96.1 & 32.72 & 177.7 & 60.04 & 29.2 & 368.2 & 1.2 \\
PLA/UP & 60.0 & 90.7 & 7.09 & 175.2 & 54.49 & 54.6 & 359.4 & 2.0 \\
PLA/GUP & 58.6 & 92.7 & 26.58 & 174.8 & 51.54 & 28.9 & 365.7 & 1.2 \\
PLA/GUP-L61 & 58.7 & 108.9 & 37.04 & 174.3 & 45.13 & 10.5 & 358.9 & 10.0 \\
PLA/MCC & 61.3 & 93.8 & 29.00 & 176.7 & 55.09 & 29.3 & 368.3 & 1.0 \\
PLA/MCC-L61 & 62.1 & 100.8 & 34.07 & 175.9 & 53.88 & 24.0 & 357.1 & 5.4 \\
\hline
\end{tabular}

Table 4 shows a substantial increase of the degree of crystallinity of the PLA films with the inclusion of cellulose fibers in its original dimension (from $29.2 \%$ to $54.6 \%$ ). The same fibers, after being ground (GUP), which have much higher fines content, provokes a substantial decrease of the crystallinity of the PLA in the film. The additional inclusion of lignin on the fibers surface causes a huge decrease of the PLA crystallinity from $28.9 \%$ to $10.5 \%$, in accordance with the lower mobility of the lignin adsorbed PLA molecules previously commented. The same trend occurs for the MCC, but with lower extent. Figure 10 shows that more and larger spherulites are formed in the PLA/UP biocomposite film than in the PLA/MCC. The higher specific surface area of the MCC (and grinded fibers) provides much higher nucleation points for crystallization, which hypothetically did not provide conditions for appropriate spherulites growing. On the contrary, the reduced number of nucleation points in UP fibers provides conditions for good spherulites growing, which led to very high crystallinity degree.
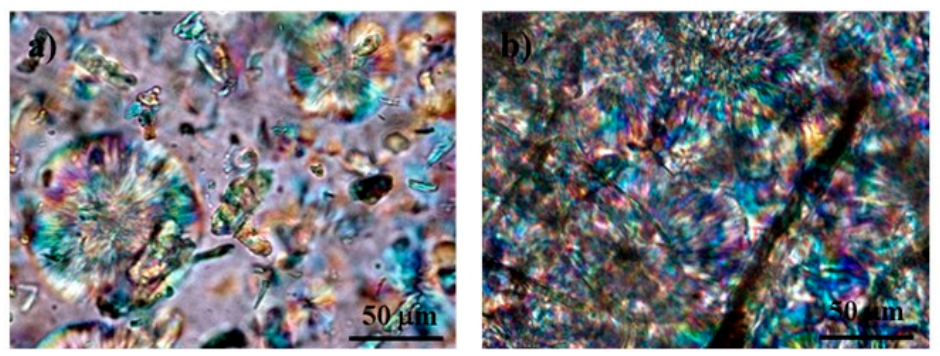

Figure 10. Polarized optical microscopy images of: (a) PLA/MCC and (b) PLA/UP biocomposite films (see Table 1 for sample identification).

Structural and mechanical properties of the PLA and composite films are presented in Tables 5 and 6 , and the images of the dispersion of the cellulose into PLA matrix examined by optical microscopy are shown in Figure 11. As can be seen in Table 5, the apparent density of the films, calculated by the basis 
weight and thickness ratio is close to the theoretical PLA density $\left(1.24 \mathrm{~g} / \mathrm{cm}^{3}\right)$ indicating the production of a practically porosity-free film.

Table 5. Structural properties of PLA/cellulose biocomposite films (see Table 1 for sample identification).

\begin{tabular}{cccc}
\hline Sample & Basis Weight $\left(\mathbf{g} / \mathbf{m}^{\mathbf{2}}\right)$ & Thickness $(\boldsymbol{\mu m})$ & Apparent Density $\left(\mathbf{g} / \mathbf{c m}^{\mathbf{3}}\right)$ \\
\hline PLA & $153.4 \pm 8.2$ & $127.8 \pm 10.2$ & $1.205 \pm 0.087$ \\
PLA/UP & $163.3 \pm 13.3$ & $134.0 \pm 12.4$ & $1.220 \pm 0.039$ \\
PLA/GUP & $152.8 \pm 10.5$ & $125.7 \pm 11.0$ & $1.218 \pm 0.037$ \\
PLA/GUP-L61 & $153.5 \pm 7.9$ & $126.3 \pm 11.1$ & $1.223 \pm 0.122$ \\
PLA/MCC & $161.9 \pm 8.0$ & $132.7 \pm 11.6$ & $1.224 \pm 0.054$ \\
PLA/MCC-L61 & $154.4 \pm 2.8$ & $127.0 \pm 4.4$ & $1.217 \pm 0.020$ \\
\hline
\end{tabular}

Tensile strength of the composite films incorporating UP, GUP and GUP-L61 does not improve when compared with the PLA film (Table 6). In the case of PLA/UP film, the loss of tensile strength is particularly relevant and is probably due to more brittle nature of the film due to the much higher crystallinity of the PLA (Table 4). The brittle nature of the film is clearly revealed in the extremely low value of toughness determined by the integration of the stress-strain curve. In turn, the incorporation of MCC and MCC-L61 improves tensile strength and, particularly, the toughness (Table 6), due to the high increase in elongation. The relatively good dispersion of the MCC in PLA matrix (Figure 11) and the high number of interface between the crystals can tentatively explain these elongations.

The toughness performance of PLA/GUP is much higher than the PLA/UP due to the lower crystallinity of the PLA. However, it is much lower than PLA/MCC probably because of the lower elongation of the PLA/GUP composite due to the restrain imposed by cellulose fiber network.

Table 6. Mechanical properties of PLA/cellulose biocomposite films (see Table 1 for sample identification).

\begin{tabular}{cccccc}
\hline Sample & $\begin{array}{c}\text { Tensile Strength } \\
\mathbf{( M P a )}\end{array}$ & $\begin{array}{c}\text { Elongation at } \\
\text { Break (\%) }\end{array}$ & $\begin{array}{c}\text { Young's } \\
\text { Modulus (GPa) }\end{array}$ & $\begin{array}{c}\text { Toughness } \\
\mathbf{( k J / \mathbf { m } ^ { 3 } )}\end{array}$ & $\begin{array}{c}\text { Bending Elastic } \\
\text { Modulus (MPa) }\end{array}$ \\
\hline PLA & $35.1 \pm 5.0$ & $2.7 \pm 0.4$ & $1.82 \pm 0.27$ & $520 \pm 78$ & $4.45 \pm 0.46$ \\
PLA/UP & $23.4 \pm 3.6$ & $1.5 \pm 0.2$ & $1.65 \pm 0.26$ & $211 \pm 49$ & $4.15 \pm 1.01$ \\
PLA/GUP & $30.6 \pm 6.8$ & $2.2 \pm 0.3$ & $1.66 \pm 0.16$ & $383 \pm 149$ & $3.83 \pm 0.63$ \\
PLA/GUP-L61 & $35.6 \pm 6.1$ & $2.3 \pm 0.4$ & $1.66 \pm 0.09$ & $408 \pm 125$ & $4.34 \pm 1.13$ \\
PLA/MCC & $43.0 \pm 3.4$ & $3.6 \pm 0.7$ & $1.53 \pm 0.18$ & $937 \pm 267$ & $4.07 \pm 0.79$ \\
PLA/MCC-L61 & $44.9 \pm 2.4$ & $3.8 \pm 0.3$ & $1.55 \pm 0.09$ & $970 \pm 129$ & $4.36 \pm 0.42$ \\
\hline
\end{tabular}
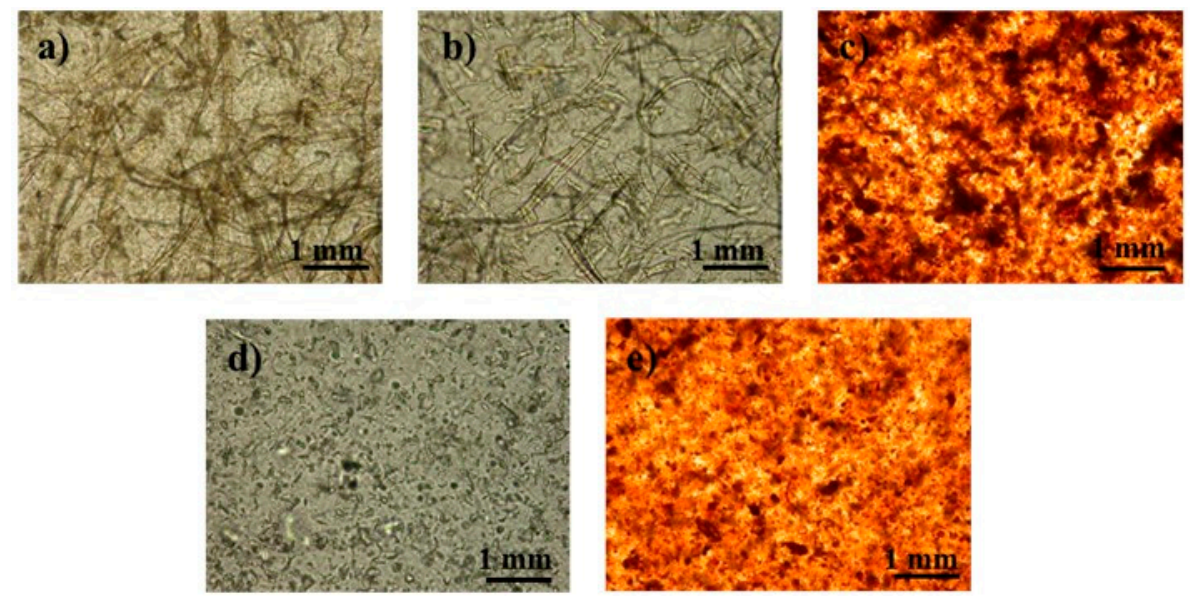

Figure 11. Optical microscopy images of the PLA/cellulose composite films: (a) PLA/UP; (b) PLA/GUP; (c) PLA/GUP-L61; (d) PLA/MCC; (e) PLA/MCC-L61 (see Table 1 for sample identification).

Contrarily to observed in the present work, Mathew et al. [9] found that PLA composites with pulp fibers have better tensile properties than those with MCC. However, pulp fibers loads are higher 
(10-25 wt \%) than that used herein. Regarding the reinforcement ability of MCC in PLA composites, the literature shows contradictory results $[9,19,57,58]$. Our results are in agreement with those obtained by Xian et al. [19], who observed that PLA composites with low MCC loads (2-6 wt \%) improved tensile strength. According to these authors, MCC can be uniformly dispersed in PLA matrix and had good interfacial bonding with PLA, as MCC has high specific surface area, surface activity and can form hydrogen bonds with PLA [19].

Concerning to Young's modulus, it was observed a decrease for the composite films when compared with PLA film, being this decrease more pronounced in the case of PLA/MCC and PLA/MCC-L61 films, in accordance with their higher elongation at break (Table 6). However, these outcomes are apparently contradictory to those reported in other studies, which found an increase of Young's modulus and the decrease of elongation at break for PLA composites reinforced with MCC $[9,19,57,58]$.

All composites show a decrease in the bending elastic modulus when compared with PLA film meaning that the composites are less stiff than PLA film.

In summary, results show that PLA/MCC composite films present better mechanical properties than that of PLA/pulp fibers composite films.

\section{Conclusions}

The solvent evaporation technique was used to produce PLA/cellulose biocomposite spheres, which were processed by compression molding. It was shown that spheres yield is primarily determined by the PVA/PLA ratio, as a suitable amount of PVA must be present in the emulsion to stabilize them, preventing the droplets coalescence. As expected, the PVA/PLA ratio required increases with the decrease of spheres size. Moreover, the increase of the hydrophobic character of the cellulose fibers led to the increase of the required PVA/PLA ratio. For the optimized PVA/PLA ratio, the spheres yield ranged from $74.0 \%$ to $87.2 \%$. The results showed the importance of cellulose surface chemistry on the spheres yield and on the percentage of cellulose incorporated. The effectiveness of cellulose fibers incorporation was improved more than 50\% when the GUP pulp fibers were surface modified with 61\% lignin (GUP-L61), in accordance with the increase of pulp fibers hydrophobicity. It was also shown that the reduction of the fiber size by grinding only increased cellulose incorporation from $31.4 \%$ to $36.0 \%$ confirming that the particle dimension is not the main parameter affecting cellulose incorporation. The average spheres size (weighted in volume) ranged from 130.9 to $888.0 \mu \mathrm{m}$ for the PLA/MCC and PLA/GUP-L61 samples, respectively. The corresponding external specific surface area, determined by laser diffraction, decreased from 579.7 to $71.1 \mathrm{~cm}^{2} / \mathrm{g}$. The BET specific surface area is, in general, two orders of magnitude higher, in accordance with the observed internal porosity of spheres by SEM. Despite this, practically porosity-free films were produced; the apparent density of the films is close to the density of the PLA used to produce the spheres. The incorporation of cellulose in its different forms led to a slightly decrease of the glass and melting temperature of the biocomposite films. The decrease is particularly noted in the cold crystallization temperature. On the other hand, the incorporation of UP fibers greatly increases the degree of crystallinity of the PLA. On the contrary, cellulose modified with lignin (GUP-L61 and MCC-L61) hinder the crystallization process (also noted in the significant increase in $T_{c c}$ ) and yields biocomposite films with lower crystallinity. The mechanical properties of the biocomposite films are affected by the cellulose type. MCC improves these properties, doubling the toughness value compared with PLA film. In contrast, the incorporation of UP fibers results in substantial loss of tensile strength and toughness due to higher PLA crystallinity in the PLA/UP film. The grinded pulp fibers originate composite films with lower crystallinity and higher tensile strength and toughness compared with UP fibers.

Author Contributions: Funding acquisition, A.C. and R.S.; Investigation, S.S.; Resources: A.S.; Supervision, R.S.; Writing—original draft, S.S.; Writing—review \& editing, A.C. and R.S.

Funding: This research was funded by [Thermocel-Desenvolvimentos de compósitos de base cellulosePOCI-01-0247-FEDER-003306] co-financed by FEDER funds through COMPETE 2020.

Conflicts of Interest: The authors declare no conflict of interest. 


\section{References}

1. Mitra, B.C. Environment friendly composite materials: Biocomposites and green composites. Def. Sci. J. 2014, 64, 244-261. [CrossRef]

2. Sahari, J.; Sapuan, S.M. Natural fibre reinforced biodegradable polymer composites. Rev. Adv. Mater. Sci. 2011, 30, 166-174.

3. Loureiro, N.C.; Esteves, J.L.; Viana, J.C.; Ghosh, S. Development of polyhydroxyalkanoates/poly(lactic acid) composites reinforced with cellulosic fibers. Compos. Part B Eng. 2014, 60, 603-611. [CrossRef]

4. Ren, H.; Zhang, Y.; Zhai, H.; Chen, J. Production and evaluation of biodegradable composites based on polyhydroxybutyrate and polylactic acid reinforced with short and long pulp fibers. Cellul. Chem. Technol. 2015, 49, 641-652.

5. Avérous, L. Polylactic Acid: Synthesis, Properties and Applications. In Monomers, Polymers and Composites from Renewable Resources; Belgacem, M.N., Gandini, A., Eds.; Elsevier Ltd.: New York, NY, USA, 2008; pp. 433-451. ISBN 978-0-08-045316-3.

6. Khalil, H.A.; Bath, A.; Yusra, A. Green composites from sustainable cellulose nanofibrils: A review. Carbohydr. Polym. 2012, 87, 963-979. [CrossRef]

7. Murariu, M.; Dubois, P. PLA composites: From production to properties. Adv. Drug Deliv. Rev. 2016, 107, 17-46. [CrossRef] [PubMed]

8. Nakagaito, A.N.; Fujimura, A.; Sakai, T.; Hama, Y.; Yano, H. Production of microfibrillated cellulose (MFC)-reinforced polylactic acid (PLA) nanocomposites from sheets obtained by a papermaking-like process. Compos. Sci. Technol. 2009, 69, 1293-1297. [CrossRef]

9. Mathew, A.P.; Oksman, K.; Sain, M. Mechanical properties of biodegradable composites from poly lactic acid (PLA) and microcrystalline cellulose (MCC). J. Appl. Polym. Sci. 2005, 97, 2014-2025. [CrossRef]

10. Cho, D.; Seo, J.M.; Lee, H.S.; Cho, C.W.; Han, S.O.; Park, W.H. Property improvement of natural fiber-reinforced green composites by water treatment. Adv. Compos. Mater. 2007, 16, 299-314. [CrossRef]

11. Le Duigou, A.; Bourmaud, A.; Balnois, E.; Davies, P.; Baley, C. Improving the interfacial properties between flax fibres and PLLA by a water fibre treatment and drying cycle. Ind. Crops Prod. 2012, 39, 31-39. [CrossRef]

12. Graupner, N. Application of lignin as natural adhesion promoter in cotton fibre-reinforced poly(lactic acid) (PLA) composites. J. Mater. Sci. 2008, 43, 5222-5229. [CrossRef]

13. Le Moigne, N.; Longerey, M.; Taulemesse, J.M.; Bénézet, J.C.; Bergeret, A. Study of the interface in natural fibres reinforced poly(lactic acid) biocomposites modified by optimized organosilane treatments. Ind. Crops Prod. 2014, 52, 481-494. [CrossRef]

14. Raj, G.; Balnois, E.; Baley, C.; Grohens, Y. Role of polysaccharides on mechanical and adhesion properties of flax fibres in flax/PLA biocomposite. Int. J. Polym. Sci. 2011, 2011, 1-11. [CrossRef]

15. Tokoro, R.; Vu, D.M.; Okubo, K.; Tanaka, T.; Fujii, T.; Fujiura, T. How to improve mechanical properties of polylactic acid with bamboo fibers. J. Mater. Sci. 2008, 43, 775-787. [CrossRef]

16. Magniez, K.; Voda, A.S.; Kafi, A.A.; Fichini, A.; Guo, Q.; Fox, B.L. Overcoming interfacial affinity issues in natural fiber reinforced polylactide biocomposites by surface adsorption of amphiphilic block copolymers. ACS Appl. Mater. Interfaces 2013, 5, 276-283. [CrossRef] [PubMed]

17. Awal, A.; Rana, M.; Sain, M. Thermorheological and mechanical properties of cellulose reinforced PLA bio-composites. Mech. Mater. 2015, 80, 87-95. [CrossRef]

18. Hua, S.; Chen, F.; Liu, Z.; Yang, W.; Yang, M. Preparation of cellulose-graft-polylactic acid via melt copolycondensation for use in polylactic acid based composites: Synthesis, characterization and properties. RSC Adv. 2016, 6, 1973-1983. [CrossRef]

19. Xian, X.; Wang, X.; Zhu, Y.; Guo, Y.; Tian, Y. Effects of MCC content on the structure and performance of PLA/MCC biocomposites. J. Polym. Environ. 2018, 26, 1-9. [CrossRef]

20. Larsson, K.; Berglund, L.A.; Ankerfors, M.; Lindström, T. Polylactide latex/nanofibrillated cellulose bionanocomposites of high nanofibrillated cellulose content and nanopaper network structure prepared by a papermaking route. J. Appl. Polym. Sci. 2012, 125, 2460-2466. [CrossRef]

21. Song, Z.; Xiao, H.; Zhao, Y. Hydrophobic-modified nano-cellulose fiber/PLA biodegradable composites for lowering water vapor transmission rate (WVTR) of paper. Carbohydr. Polym. 2014, 111, 442-448. [CrossRef]

22. Wang, T.; Drzal, L.T. Cellulose-nano fiber-reinforced poly(lactic acid) composites prepared by a water-based approach. ACS Appl. Mater. Interfaces 2012, 4, 5079-5085. [CrossRef] [PubMed] 
23. Iwatake, A.; Nogi, M.; Yano, H. Cellulose nanofiber-reinforced polylactic acid. Compos. Sci. Technol. 2008, 68, 2103-2106. [CrossRef]

24. Yu, H.Y.; Zhang, H.; Song, M.L.; Zhou, Y.; Yao, J.; Ni, Q.Q. From cellulose nanospheres, nanorods to nanofibers: Various aspect ratio induced nucleation/reinforcing effects on polylactic acid for robust-barrier food packaging. ACS Appl. Mater. Interfaces 2017, 9, 43920-43938. [CrossRef] [PubMed]

25. Hossain, K.M.Z.; Ahmed, I.; Parsons, A.J.; Scotchford, C.A.; Walker, G.S.; Thielemans, W.; Rudd, C.D. Physico-chemical and mechanical properties of nanocomposites prepared using cellulose nanowhiskers and poly(lactic acid). J. Mater. Sci. 2012, 47, 2675-2686. [CrossRef]

26. Lee, K.Y.; Blaker, J.J.; Bismarck, A. Surface functionalisation of bacterial cellulose as the route to produce green polylactide nanocomposites with improved properties. Compos. Sci. Technol. 2009, 69, 2724-2733. [CrossRef]

27. Immonen, K.; Lahtinen, P.; Pere, J. Effects of Surfactants on the Preparation of Nanocellulose-PLA Composites. Bioengineering 2017, 4, 91. [CrossRef]

28. Ghasemi, S.; Behrooz, R.; Ghasemi, I.; Yassar, R.S.; Long, F. Development of nanocellulose-reinforced PLA nanocomposite by using maleated PLA (PLA-g-MA). J. Thermoplast. Compos. Mater. 2018, 31, 1090-1101. [CrossRef]

29. Graupner, N.; Albrecht, K.; Hegemann, D.; Müssig, J. Plasma modification of man-made cellulose fibers (Lyocell) for improved fiber/matrix adhesion in poly(lactic acid) composites. J. Appl. Polym. Sci. 2013, 128, 4378-4386. [CrossRef]

30. Gu, J.; Catchmark, J.M. Polylactic acid composites incorporating casein functionalized cellulose nanowhiskers. J. Biol. Eng. 2013, 7, 31. [CrossRef]

31. Frone, A.N.; Berlioz, S.; Chailan, J.-F.; Panaitescu, D.M.; Donescu, D. Cellulose fiber-reinforced polylactic acid. Polym. Compos. 2011, 32, 976-985. [CrossRef]

32. Graupner, N.; Fischer, H.; Ziegmann, G.; Müssig, J. Improvement and analysis of fibre/matrix adhesion of regenerated cellulose fibre reinforced PP-, MAPP- and PLA-composites by the use of Eucalyptus globulus lignin. Compos. Part B Eng. 2014, 66, 117-125. [CrossRef]

33. Wang, X.; Jia, Y.; Liu, Z.; Miao, J. Influence of the lignin content on the properties of poly(lactic acid)/lignin-containing cellulose nanofibrils composite films. Polymers (Basel) 2018, 10, 1013. [CrossRef]

34. Nair, S.S.; Chen, H.; Peng, Y.; Huang, Y.; Yan, N. Polylactic acid biocomposites reinforced with nanocellulose fibrils with high lignin content for improved mechanical, thermal, and barrier properties. ACS Sustain. Chem. Eng. 2018, 6, 10058-10068. [CrossRef]

35. Oksman, K.; Aitomäki, Y.; Mathew, A.P.; Siqueira, G.; Zhou, Q.; Butylina, S.; Tanpichai, S.; Zhou, X.; Hooshmand, S. Review of the recent developments in cellulose nanocomposite processing. Compos. Part A Appl. Sci. Manuf. 2016, 83, 2-18. [CrossRef]

36. Samir, M.A.S.A.; Alloin, F.; Dufresne, A. Review of recent research into cellulosic whiskers, their properties and their application in nanocomposite field. Biomacromolecules 2005, 6, 612-626. [CrossRef]

37. Mesic, N.; Friman, A. Process for Manufacturing a Composition Comprising Cellulose Pulp Fibers and Thermoplastic Fibers. U.S. Patent 9,297,112, 29 March 2013.

38. Freitas, S.; Merkle, H.P.; Gander, B. Microencapsulation by solvent extraction/evaporation: Reviewing the state of the art of microsphere preparation process technology. J. Controll. Release 2005, 102, 313-332. [CrossRef]

39. Hong, Y.; Gao, C.; Shi, Y.; Shen, J. Preparation of porous polylactide microspheres by emulsion-solvent evaporation based on solution induced phase separation. Polym. Adv. Technol. 2005, 16, 622-627. [CrossRef]

40. Lee, I.; Ji, S. Device and Method for Encapsulation of Hydrophilic Materials. U.S. Patent 9308172, 12 April 2016.

41. Guay, D.; Sutherland, N.; Rantanen, W.; Malandri, N.; Stephens, A.; Mattingly, K.; Schneider, M. Comparison of fiber length analyzers. In Proceedings of the 2005 TAPPI Practical Papermaking Conference, Milwaukee, WI, USA, 22-26 May 2005; Tappi Press: Atlanta, GA, USA, 2005.

42. Jiang, X.; Zhou, C.; Tang, K. Preparation of PLA and PLGA nanoparticles by binary organic solvent diffusion method. J. Cent. South. Univ. Technol. 2003, 10, 202-206. [CrossRef]

43. Sullivan, E.M.; Moon, R.J.; Kalaitzidou, K. Processing and characterization of cellulose nanocrystals/polylactic acid nanocomposite films. Materials 2015, 8, 8106-8116. [CrossRef] 
44. Kajanto, I. Structural mechanisms of paper and board. In Papermaking Science and Technology-Paper Physics; Niskanen, K., Ed.; Fapet Oy in cooperation with the Paper Engineers' Association and TAPPI: Helsinki, Finland, 1998; pp. 192-221, ISBN 10: 9525216160, ISBN 13: 9789525216165.

45. Maa, Y.F.; Hsu, C.C. Effect of primary emulsions on microsphere size and protein-loading in the double emulsion process. J. Microencapsul. 1997, 14, 225-241. [CrossRef]

46. Al-Azzam, W.; Pastrana, E.A.; Griebenow, K. Co-lyophilization of bovine serum albumin (BSA) with poly(ethylene glycol) improves efficiency of BSA encapsulation and stability in polyester microspheres by a solid-in-oil-in-oil technique. Biotechnol. Lett. 2002, 24, 1367-1374. [CrossRef]

47. Ludueña, L.N.; Vecchio, A.; Stefani, P.M.; Alvarez, V.A. Extraction of cellulose nanowhiskers from natural fibers and agricultural byproducts. Fibers Polym. 2013, 14, 1118-1127. [CrossRef]

48. Pandey, K.K. A study of chemical structure of soft and harwood and wood polymers by FTIR spectrscopy. J. Appl. Polym. Sci. 1999, 71, 1969-1975. [CrossRef]

49. Kister, G.; Cassanas, G.; Vert, M. Effects of morphology, conformation and configuration on the IR and Raman spectra of various poly(lactic acid)s. Polymer 1998, 39, 267-273. [CrossRef]

50. Gordobil, O.; Delucis, R.; Egüés, I.; Labidi, J. Kraft lignin as filler in PLA to improve ductility and thermal properties. Ind. Crops Prod. 2015, 72, 46-53. [CrossRef]

51. Darie-Niţə, R.N.; Vasile, C.; Irimia, A.; Lipşa, R.; Râpa, M. Evaluation of some eco-friendly plasticizers for PLA films processing. J. Appl. Polym. Sci. 2016, 133, 1-11. [CrossRef]

52. Maximova, N.; Österberg, M.; Koljonen, K.; Stenius, P. Lignin adsorption on cellulose fibre surfaces: Effect on surface chemistry, surface morphology and paper strength. Cellulose 2001, 8, 113-125. [CrossRef]

53. Mathew, A.P.; Oksman, K.; Sain, M. The Effect of morphology and chemical characteristics of cellulose reinforcements on the crystallinity of polylactic acid. J. Appl. Polym. Sci. 2006, 101, 300-310. [CrossRef]

54. Frone, A.N.; Berlioz, S.; Chailan, J.F.; Panaitescu, D.M. Morphology and thermal properties of PLA-cellulose nanofibers composites. Carbohydr. Polym. 2013, 91, 377-384. [CrossRef]

55. Watkins, D.; Nuruddin, M.; Hosur, M.; Tcherbi-Narteh, A.; Jeelani, S. Extraction and characterization of lignin from different biomass resources. J. Mater. Res. Technol. 2015, 4, 26-32. [CrossRef]

56. Li, J.; He, Y.; Inoue, Y. Thermal and mechanical properties of bodegradable blends of poly(L-lactic acid) and lignin. Polym. Int. 2003, 52, 949-955. [CrossRef]

57. Haafiz, M.K.M.; Hassan, A.; Zakaria, Z.; Inuwa, I.M.; Islam, M.S.; Jawaid, M. Properties of polylactic acid composites reinforced with oil palm biomass microcrystalline cellulose. Carbohydr. Polym. 2013, 98, 139-145. [CrossRef] [PubMed]

58. Abdulkhani, A.; Hosseinzadeh, J.; Dadashi, S.; Mousavi, M. A study of morphological, thermal, mechanical and barrier properties of PLA based biocomposites prepared with micro and nano sized cellulosic fibers. Cellul. Chem. Technol. 2015, 49, 7-8.

(C) 2019 by the authors. Licensee MDPI, Basel, Switzerland. This article is an open access article distributed under the terms and conditions of the Creative Commons Attribution (CC BY) license (http:/ / creativecommons.org/licenses/by/4.0/). 